\title{
A Meta-analysis of the Effect of the Sandwich Teaching Model on the Learning Outcomes of Nursing Students
}

\author{
Yanqiu Hao, Xiangshu Cui* \\ Nursing School, YanBian University, Jilin 133000, China
}

\begin{abstract}
[Abstract] Objective: To evaluate the effect of the sandwich teaching model on the learning effect of nursing students. Methods: The Chinese and English databases of CNKI, WanFang, Vip, superstar, and PubMed were searched by computer, and the data were analyzed by Rev Man 5.3 software after literature quality evaluation. Results: Meta-analysis showed that the theoretical and operational performance of the nursing students in the sandwich teaching method was better than that of the traditional teaching group. Conclusion: The sandwich approach was superior to the traditional teaching method in the learning outcomes of nursing students.
\end{abstract}

Keywords: Nursing students; Sandwich teaching; Learning outcomes; Nursing education; Meta-analysis

Publication date: May, 2021; Publication online: 31 May, 2021

*Corresponding author: Xiangshu Cui, 18754778520@163.com

\section{Introduction}

In the notice on the issuance of the national nursing career development plan (2016-2020), it is mentioned that "China's economic and social development has entered the normal state, the aging of the population is intensifying, the new type of urbanization is accelerating, and the supply-side structural reform has further released the health needs of the public" ${ }^{[1]}$. In the face of various challenges and opportunities, nursing talents training should shift from knowledge-based and skill-based to adaptive and application-oriented talents. The sandwich course, a teaching-practice-teaching model, was first proposed in the United Kingdom, where theoretical learning and work practice are integrated with each other ${ }^{[2]}$. The Sandwich is not widely used in the classroom ${ }^{[3]}$. This study compares the effects of sandwich and traditional teaching methods on nursing students' learning outcomes using meta-analysis ${ }^{[4]}$. This study was designed to provide a theoretical basis for the future clinical development of sandwich teaching.

\section{Materials and methods}

\subsection{Literature search strategy}

CNKI, WanFang, Vip, Chaoxing, PubMed, and other Chinese and English databases were searched to collect relevant randomized controlled trials on the effect of sandwich teaching on the learning effect of nursing professionals, and the search period was from the establishment of each database to April 19, 2020. Also, the grey literature was searched through Google. The search was a combination of free words and subject terms. Search terms included: sandwich; sandwich course; nursing; nurse, etc.

\subsection{Literature inclusion and exclusion criteria}

\subsubsection{Types of research}

Inclusion in published randomized controlled trials.

\subsubsection{Inclusion of subjects}

The subjects include full-time nursing professionals or clinical interns of any race, nationality, or education who volunteer to participate.

\subsubsection{Interventions}

Conventional teaching group: Traditional teaching methods are used. Experimental group: using the sandwich teaching model.

\subsubsection{Outcome indicators}

Theoretical and practical examinations and related 
questionnaires are administered uniformly at the end of the course.

\subsubsection{Exclusion criteria}

The original research data could not be extracted and could not be extracted after contacting the authors.

\subsection{Literature screening and data extraction}

Two evaluators independently screened the literature, extracted and cross-checked the data, and in case of disagreement, a third party was consulted to assist in judging the literature. In the literature screening, the title and abstract were read first, and after excluding obviously irrelevant literature, the full text was further read to determine the final inclusion.

\subsection{Risk of bias evaluation of inclusion studies}

The risk of bias of the included studies was evaluated by two evaluators according to the Cochrane 5.3.5 Handbook for Risk of Bias Assessment Tools for Randomized Controlled Trials.

\subsection{Statistical methods}

RevMan 5. 3 was used for data analysis. For continuous variables, when the measures or units of the effects of the same intervention were identical, WMD was chosen; otherwise, SMD was chosen as the combined statistic. (1) Heterogeneity: When $P>0.1$ and $\mathrm{I}^{2}<50 \%$, the fixed-effect model was used; when $P<0.1$ and $\mathrm{I}^{2} \geq 50 \%$, the random effect model was chosen; when $P<0.1$ and the source of heterogeneity could not be determined, the random effect model was used. Use a descriptive analysis. (2) Sensitivity analysis: If necessary, test the stability of the results by removing a large sample of data or a sample with a smaller validity scale to see if the combined effect size changes significantly. (3) Publication bias: A funnel plot is used to detect publication bias. If the scatter is symmetrical on both sides of the funnel plot, publication bias is insignificant; otherwise, publication bias is large.

\section{Results}

\subsection{Literature screening process}

A total of 589 articles were searched, and after the screening, 12 studies were finally included, involving a total of 1,233 subjects, and the literature screening process and results (see Figure 1).

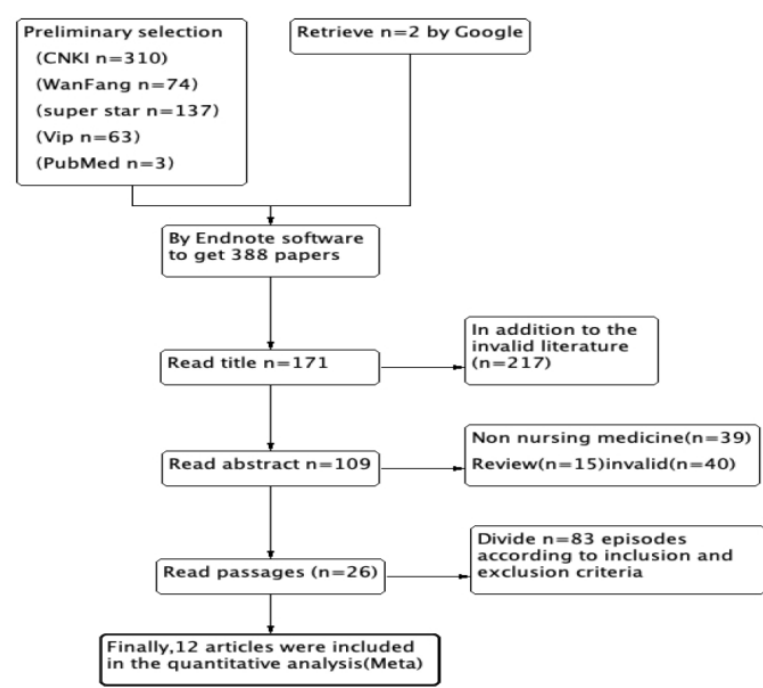

Figure 1. Literature screening process and results

\subsection{Basic characteristics of included studies and risk of bias evaluation results}

The basic characteristics of the included studies and the evaluation of methodological quality are shown in Table 1.

Table 1. Basic characteristics of the included studies

\begin{tabular}{|c|c|c|c|c|c|c|c|c|}
\hline \multirow{2}{*}{ Included study } & \multirow{2}{*}{$\begin{array}{c}\text { Research } \\
\text { design }\end{array}$} & \multicolumn{2}{|c|}{ Sample size } & \multirow{2}{*}{$\begin{array}{c}\text { Research } \\
\text { objects }\end{array}$} & \multicolumn{2}{|c|}{$\begin{array}{c}\text { Intervention } \\
\text { measures }\end{array}$} & \multirow{2}{*}{$\begin{array}{l}\text { Intervention } \\
\text { time(month) }\end{array}$} & \multirow{2}{*}{ Outcome } \\
\hline & & $\mathbf{T}$ & $\mathbf{C}$ & & $\mathbf{T}$ & $\mathbf{C}$ & & \\
\hline $\operatorname{Ren} 2019^{[4]}$ & $\mathrm{RCT}$ & 20 & 20 & inter & $\mathrm{a}$ & $\mathrm{b}$ & unspecified & $\mathrm{jk}$ \\
\hline Liu2018 $8^{[5]}$ & $\mathrm{RCT}$ & 62 & 62 & internal & $\mathrm{a}$ & $\mathrm{b}$ & 12 & $\mathrm{jk}$ \\
\hline Peng2015 & $\mathrm{RCT}$ & 36 & 42 & internal & $\mathrm{a}$ & $\mathrm{b}$ & unspecified & $\mathrm{jk}$ \\
\hline Fang2013 ${ }^{[7]}$ & $\mathrm{RCT}$ & 50 & 50 & internal & $\mathrm{a}$ & $\mathrm{b}$ & 2 & $\mathrm{jk}$ \\
\hline $\operatorname{Li} 2018^{[8]}$ & $\mathrm{RCT}$ & 40 & 40 & inter & $\mathrm{a}$ & $\mathrm{b}$ & 1 & $\mathrm{jk}$ \\
\hline Xiao2018 ${ }^{[9]}$ & $\mathrm{RCT}$ & 94 & 90 & internal & $\mathrm{a}$ & $\mathrm{b}$ & 6 & $\mathrm{jk}$ \\
\hline Jiang2018 $8^{[10]}$ & $\mathrm{RCT}$ & 30 & 30 & internal & $\mathrm{a}$ & $\mathrm{b}$ & 12 & $\mathrm{jkl}$ \\
\hline Yu2017[11] & $\mathrm{RCT}$ & 36 & 36 & internal & $\mathrm{a}$ & $\mathrm{b}$ & 1 & $\mathrm{jk}$ \\
\hline Lu2018 $8^{[12]}$ & $\mathrm{RCT}$ & 54 & 55 & internal & $\mathrm{a}$ & $\mathrm{b}$ & unspecified & $\mathrm{jk}$ \\
\hline
\end{tabular}




\begin{tabular}{|c|c|c|c|c|c|c|c|c|}
\hline Chen2014[13] & $\mathrm{RCT}$ & 80 & 88 & internal & $\mathrm{a}$ & $\mathrm{b}$ & unspecified & $\mathrm{jk}$ \\
\hline Chen2013[14] & RCT & 49 & 49 & internal & $\mathrm{a}$ & $\mathrm{b}$ & unspecified & $\mathrm{jk}$ \\
\hline Long2016 $6^{[15]}$ & $\mathrm{RCT}$ & 60 & 60 & internal & $\mathrm{a}$ & $\mathrm{b}$ & unspecified & $\mathrm{jkl}$ \\
\hline
\end{tabular}

T: Experimental group; C: Control group; a: Sandwich teaching method; b: Traditional teaching method; j: Theoretical achievements; k: Operational performance; 1:Degree of satisfaction

Table 2. Methodological quality assessment of the included studies

\begin{tabular}{|c|c|c|c|c|c|c|}
\hline $\begin{array}{c}\text { Included } \\
\text { study }\end{array}$ & $\begin{array}{c}\text { Random } \\
\text { Sequence } \\
\text { Generation }\end{array}$ & $\begin{array}{c}\text { Allocation } \\
\text { concealment }\end{array}$ & $\begin{array}{c}\text { Blind } \\
\text { method }\end{array}$ & $\begin{array}{c}\text { Outcome data } \\
\text { integrity }\end{array}$ & $\begin{array}{l}\text { Selective } \\
\text { reporting }\end{array}$ & Other bias \\
\hline $\operatorname{Ren} 2019^{[4]}$ & Low-risk bias & Unclear & Unclear & Yes & Low-risk bias & Unclear \\
\hline Liu2018 $8^{[5]}$ & Low-risk bias & Unclear & Unclear & Yes & Low-risk bias & Unclear \\
\hline Peng2015 $[6]$ & Low-risk bias & Unclear & Unclear & Yes & Low-risk bias & Unclear \\
\hline Fang2013[7] & Low-risk bias & Unclear & Unclear & Yes & Low-risk bias & Unclear \\
\hline $\mathrm{Li} 2018^{[8]}$ & Low-risk bias & Unclear & Unclear & Yes & Low-risk bias & Unclear \\
\hline Xiao2018 $8^{[9]}$ & Low-risk bias & Unclear & $\begin{array}{c}\text { Low-risk } \\
\text { bias }\end{array}$ & Yes & Low-risk bias & Unclear \\
\hline Jiang2018 $8^{[10]}$ & Low-risk bias & Unclear & Unclear & Yes & Low-risk bias & Unclear \\
\hline Yu2017 $[11]$ & Low-risk bias & Unclear & Unclear & Yes & Low-risk bias & Unclear \\
\hline Lu2018 $8^{[12]}$ & Low-risk bias & Unclear & Unclear & Yes & Low-risk bias & Unclear \\
\hline Chen2014 $[13]$ & Low-risk bias & Unclear & Unclear & Yes & Low-risk bias & Unclear \\
\hline Chen2013 ${ }^{[14]}$ & Low-risk bias & Unclear & Unclear & Yes & Low-risk bias & Unclear \\
\hline Long2016 ${ }^{[15]}$ & Low-risk bias & Unclear & Unclear & Yes & Low-risk bias & Unclear \\
\hline
\end{tabular}

\subsection{Effects of sandwich teaching method on the theoretical performance of nursing students}

\subsubsection{Meta-analysis results}

The results of the meta-analysis showed that the theoretical performance of the sandwich teaching group was higher than that of the traditional teaching group $[\mathrm{SMD}=1.34,94 \%$ CI(0.88-1.80), $\mathrm{p}<0.05$ ]. 0.00001] (see Figure 2). There was heterogeneity across studies $(\mathrm{p}<0.00001, \mathrm{I} 2=94 \%)$, which may be related to the quality of the included literature.

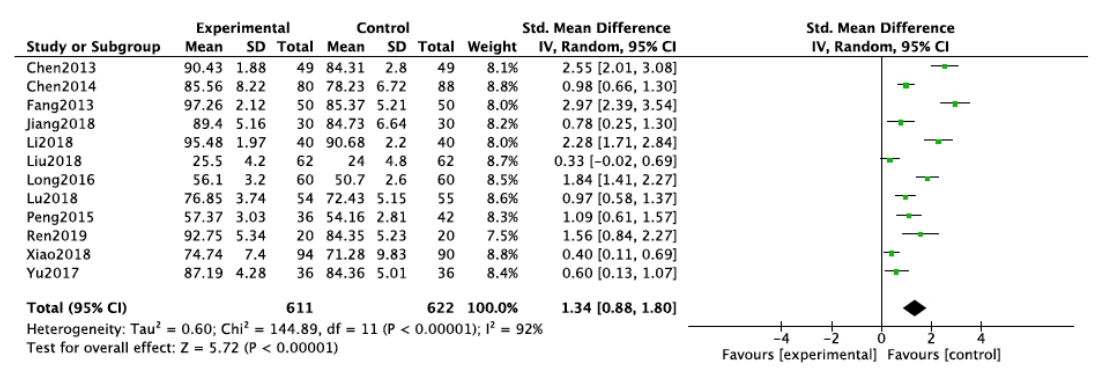

Figure 2. Meta-analysis of the comparison of theoretical achievement scores between the sandwich and traditional teaching groups

\subsubsection{Publication bias and sensitivity analysis}

A funnel plot analysis of the 12 papers found that the scatter on both sides of the paper was basically symmetrical with no obvious publication bias (see Figure 3). 


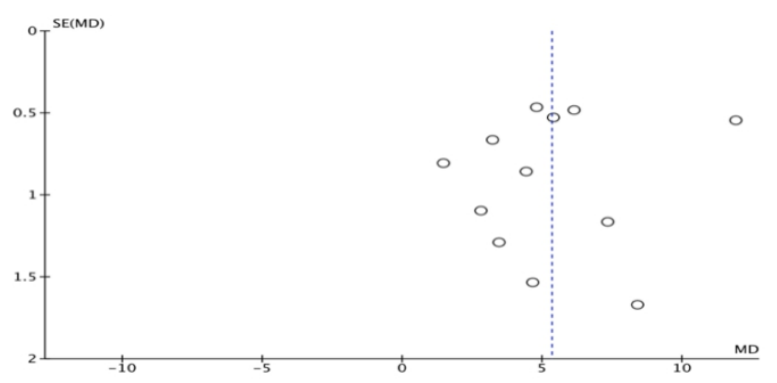

Figure 3. Funnel plot analysis of the 12 papers

\subsection{Effects of sandwich teaching methods on nursing student performance.}

\subsubsection{Meta-analysis results}

Twelve ${ }^{[4-15]}$ papers were included to compare the effect of sandwich teaching on the performance of nursing students. A total of 1233 subjects with $\mathrm{I} 2=95 \%$ were studied, so a random-effects model was used and the results of the meta-analysis showed that the sandwich teaching group was better than the traditional teaching group $[\mathrm{SMD}=1.41$, 94\% CI(3.37-7.35), $\mathrm{p}<0.00001]$ (Figure 4).

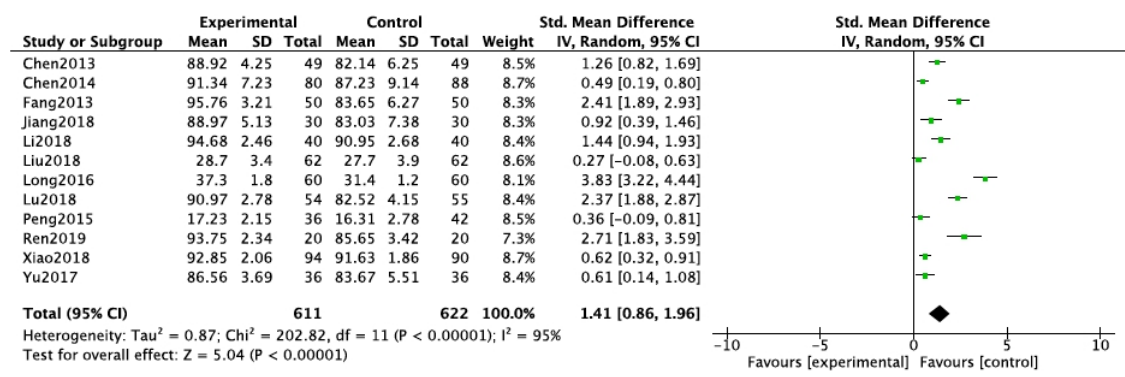

Figure 4. A meta-analysis of the performance of nursing students in the sandwich teaching group and the traditional teaching group

\subsubsection{Publication bias and sensitivity analysis}

The funnel plot analysis of $12^{[4-15]}$ papers found that the scatter on both sides was basically symmetrical, with no obvious publication bias (see Figure 5), and the direction of the sensitivity analysis results did not change after deleting one data item.

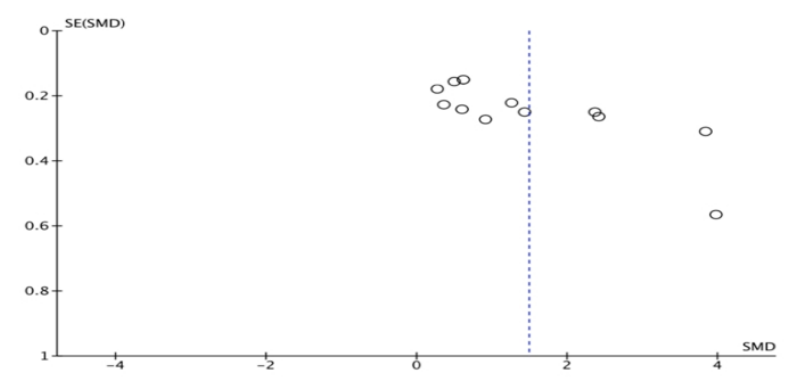

Figure 5. Funnel plot of the effect of the sandwich teaching group on operational performance 2.5 Evaluation of nurses' satisfaction with the sandwich teaching method

The sandwich teaching group's satisfaction with the teaching effect, including the impact on the learning attitude, self-learning ability, interpersonal communication ability, and thinking style, etc. The content and methods of satisfaction evaluation differed greatly among studies, so the satisfaction data could not be combined quantitatively, and only descriptive analysis was conducted.

\section{Discussion}

\subsection{Quality of the methods included in the study}

There is a difference in the quality of the 12 papers included in this study. All 12 papers are RCTs, and the use of blinding can make the results more objective and reliable, but only one of the 12 papers shows that none of the other papers is blinded, so there is a possibility of bias. ", which may be related to inconsistencies in the timing and frequency of interventions included and differences in the content of the instructional curriculum. Furthermore, the sandwich pedagogy is suitable for small class sizes, and current school-based nursing education is more likely to be taught in large classes, which may also lead to limitations in the study. However, there is almost no meta-analysis of current research on sandwich teaching, so this study still strictly follows the meta-analysis method to analyze the included literature, hoping that sandwich teaching can be further improved in the field of nursing education.

\subsection{Effects of sandwich teaching on nursing students' learning outcomes}

The results of the meta-analysis showed that compared with the traditional teaching method, the sandwich method can improve nursing students' theoretical performance, operational performance, general performance, learning interest, and thinking ability, and has advantages in critical thinking, practical ability, and teaching satisfaction. The presence of bias is less likely to occur. Therefore, it is 
plausible that this study concluded that the sandwich approach better facilitated nursing students' learning outcomes.

\subsection{Limitations of the inclusion study and implications for future research}

Due to the limitations, although this study searched Pubmed and other databases, it did not obtain the standard English data, so it is incomplete. Secondly, due to language limitation, only Chinese and English languages were included in this study, which may lead to selective bias, and it is recommended to collect more comprehensive data in the future.

\subsection{Summary}

The nursing profession is a subject that combines theory and practice, which not only focuses on the mastery of theoretical knowledge but also cultivates applied talents. This study confirms that the sandwich teaching method can stimulate learning interest, improve efficiency, develop evidence-based thinking, and improve interpersonal communication skills, critical thinking, and teamwork, and more than $90 \%$ of students believe that the sandwich teaching method is better than other teaching methods ${ }^{[4,6,12]}$. The sandwich teaching method tends to be small class teaching. However, the sandwich teaching method tends to be a small class, and in the study of Wang et al. Therefore, in the future, we must prefer a hybrid teaching method that combines online and sandwich teaching models.

\section{References}

[1] National Health Planning Commission "National Nursing Development Plan (2016-2020) Notice" National Health Medical Development (2016) No. 64 [EB/OL] http://www.nhc.gov.cn/yzygj/s3593/201611/92b2e8f8cc 644a899e9d0fd572aefef3.shtml

[2] Zheng XM. The application of the "sandwich" teaching method in higher education[J].

[3] Zhang Shan. Application of sandwich teaching method in nursing management[D]. Chengdu University of Chinese Medicine, 2014.

[4] Ren L, Zhang J, Ning Q, Zhang L, Liu XY. Application of sandwich combined surgical observation method in nursing education in vascular surgery[J]. Health Professions Education,2019,37(11):90-91.

[5] Liu L. Observation on the application of the "sandwich" teaching method in teaching anatomy in nursing $[\mathrm{J}]$. Massage and Rehabilitation Medicine,2018,9(7):91-92. doi:10.3969/j.issn.1008-1879.2018.07.044.

[6] Peng QJ, Xin LP, Chen YY. Effectiveness of the "sandwich" teaching method in internal medicine nursing of undergraduate nursing $[\mathrm{J}]$. Continuing Medical Education,2015,29(01):25-26.

[7] Fang SR,Xie GY. Practice and application of the sandwich teaching method in nursing education $[\mathrm{J}]$. Chinese Journal of Health Care and Nutrition, 2013,23(6):3326-3327. doi:10.3969/j.issn.1004-7484(x).2013.06.572.

[8] Li Q, Li LM, Du YE, et al. Application of "sandwich" combined with case teaching in clinical teaching of surgical nursing $[\mathrm{J}]$. Family Practice Nursing,2018,16(2):235-236. doi:10.3969/j.issn.1674-4748.2018.02.047.

[9] Xiao WH,Qiu XY, Lou SH, et al. The application of sandwich teaching method in the practice teaching of Chinese medicine nursing technology[J]. Chinese Nursing Education,2018,15(4):283-286. doi:10.3761/j.issn.1672-9234.2018.04.009.

[10] Jiang Y,Tu H. Application of improved sandwich teaching method in clinical nursing education[J]. Health Care Literature,2018,(5):65,110. DOI:10.3969/j.issn.1671-5217.2018.05.063.

[11] Yu TT,Wang J. Application of "sandwich" teaching method in teaching nursing practice in emergency department $[\mathrm{J}]$. Contemporary Nursing (Midterm), 2017,(10):151-154.

[12] The application of Sandwich teaching method in pre-practicum skills training for nursing students $[\mathrm{J}]$ Journal of Nursing,2018,25(22):6-10. doi:10.16460/j.issn1008-9969.2018.22.006.

[13] The application of Sandwich teaching method in the practice teaching of obstetrics and gynecology nursing $[\mathrm{J}]$. Nursing Practice and Research,2014,11(01):103-104.

[14] Chen QS. Application of case discussion class based on "sandwich" teaching idea in surgical nursing[J]. Science and Technology Information, 2013,(9):139-140. DOI:10.3969/j.issn.1001-9960.2013.09.095.

[15] Long HY, Lv Y, Fan LJ, Xiong SM, Lan Y. Application and practice of the "sandwich" teaching model in adult health nursing[J]. Nursing Research,2016,30(28):3521-3523. 
[16] The application of Sandwich teaching method in clinical practice mini-lecture for undergraduate nursing students[J]. China Continuing Medical Education, 2019,11(26):16-19.

[17] Comparison of Sandwich and PBL teaching method in diagnostic teaching practice[J]. Journal of PLA Hospital Management, 2015,22(02):167-169.

[18] Wang YG. The application of sandwich teaching method based on Internet interactive platform in nursing clinical teaching[D]. Chongqing Medical University, 2017.

[19] Wang WW. Application of "sandwich" teaching method and "WeChat" micro-teaching in neurological examination training[J]. China Higher Medical Education,2015(03):52-53. 